\title{
ANA DE CASTRO OSÓRIO, UNA MUJER QUE TRASPASÓ FRONTERAS: SOBRE UNOS TEXTOS OLVIDADOS EN LA ESPAÑOLA

\author{
REVISTA DE LA RAZA ${ }^{1}$
}

ÁNGELES EZAMA GIL

Universidad de Zaragoza aezama@unizar.es

RESUMEN: Este trabajo no supone una investigación original pero sí la presentación de algunos textos que la escritora portuguesa Ana de Castro Osório publicó en la española Revista de la Raza, en su lengua materna (circunstancia nada habitual en tal publicación), que ofrezco debidamente contextualizados. Esta colaboración se inscribe en el marco de la relación personal que Ana de Castro mantuvo con la escritora española Carmen de Burgos, directora de la Liga Internacional de Mujeres Ibéricas e Iberoamericanas, de la que Burgos era presidenta, la Revista de la Raza portavoz y Ana de Castro secretaria de la sección portuguesa. Los textos de Ana de Castro que ahora se recuperan recogen las preocupaciones fundamentales de la escritora: la atención a la infancia mediante la edición de colecciones de cuentos infantiles, el ideal lusista de fusión entre Portugal y Brasil (también en algún sentido el ibérico de unión entre Portugal y España) y su interés por la causa de la mujer; en todas estas cuestiones la visión de Castro es profundamente integradora y marcadamente nacionalista.

PALABRAS CLAVE: Ana de Castro Osório, Revista de la Raza, Carmen de Burgos, literatura infantil, lusismo, feminismo.

${ }^{1}$ Este artículo se inscribe en el marco del proyecto "La Re(d) pública de las Letras: redes de sociabilidad y asociacionismo femenino en el campo cultural contemporáneo (1834-1931)" (FFI201017273; CSIC-Ministerio de Ciencia e Innovación). 


\section{ANA DE CASTRO OSÓRIO, A WOMAN WHO CROSSED BORDERS: some Forgotten Texts on the Spanish Revista de la Raza}

ABSTRACT: This essay presents contextualized texts that the Portuguese writer Ana de Castro Osório published in the Spanish Revista de la Raza [Journal of the Race] written in her own language, something very rare in such a publication. Her collaboration was made possible by the personal connection between Ana de Castro and the Spanish writer Carmen de Burgos, head of the Liga Internacional de Mujeres Ibéricas e Iberoamericanas [Iberian and Latin American International Women's League]. Carmen de Burgos was Chair of the League, whilst Ana de Castro was the secretary of the Portuguese section and the Journal of the Race, the League's mouthpiece. Ana de Castro's recovered texts reflect the writer's main concerns: her attention to childhood through her editions of collections of fairy tales, the ideal of fusion between Portugal and Brazil (even the union between Portugal and Spain is suggested) and her interest in feminist movements. Castro's perspective on all these issues is holistic and distinctly nationalistic.

KEYWORDS: Ana de Castro Osório. Revista de la Raza. Carmen de Burgos. Children's Literature. Portugese-Brazilian Nationalism. Feminism.

a portuguesa Ana de Castro Osório es, a lo que parece, uno de esos nombres imprescindibles en la historia de la literatura, en la de la lucha de las mujeres y en la del lusismo, que, paradójicamente, sólo hace unos pocos años ha empezado a ser reivindicada dentro de este contexto, gracias fundamentalmente a los trabajos de João Esteves, quien señala:

está ainda por realizar o estudo exaustivo do seu percurso e legado nos diferentes níveis de intervenção $[\ldots]$

Se a importância literária de Ana de Castro Osório pode ser questionada, já o impacto que produz na vida cultural portuguesa não pode ser ignorado ou menosprezado, com dezenas de obras publicadas, que conheceran inúmeras edições. (Esteves, 2003: 1019)

Del mismo modo, en un trabajo de 2006 (118-122), Edfelt señala que tanto Castro como otras escritoras de la Primera República no suelen estar presentes en las historias de la literatura, y, cuando figuran, es a menudo en su condición de autoras de literatura infantil. No obstante, estudios más recientes como el de Cordeiro (2012) contribuyen a dar una imagen de la publicista portuguesa más ajustada a su realidad, tanto ideológica como social, a través del análisis de sus discursos teóricos y de sus relatos de ficción.

Sorprenden los numerosos parecidos que es dado encontrar entre ella y la española Carmen de Burgos; ambas luchan por las mismas causas (pacifismo, abolicionismo, derecho al divorcio y al voto), tienen idéntica vocación pedagógica (Esteves, 2003), hacen profesión de fe republicana, militan en la masonería (Ballesteros, 2005), crean asociaciones feministas, y expresan sus inquietudes por medio de la escritura (Ezama, en prensa ${ }^{2}$ ) y del discurso (conferencias ${ }^{3}$ ); protagonistas de un mismo tiempo histórico, los viajes, la pertenencia común a algunas asociaciones y los lazos de amistad personal, acabarían abriendo una grieta en esa frontera entre dos países colindantes pero a menudo ignorantes uno del otro. Como ya señalé en un trabajo anterior, creo que Carmen de Burgos y Ana de Castro, al igual que otras contemporáneas suyas, fueron capaces de superar las barreras políticas y económicas para establecer una suerte de comunidad espiritual que permitió la comunicación en un ambiente de ignorancia común bastante considerable; de ello son un indicio alentador los trabajos de Ballesteros (2003, 2006), Ezama (2010) y Esteves (2011).

Carmen de Burgos le hizo una entrevista en octubre de 1915 en la

${ }^{2}$ Ambas fueron pioneras del periodismo. Carmen de Burgos así lo expresa en una entrevista que le hizo en 1922 Enrique González Fiol: "Sin vanidad puedo decir que así como a los reyes se les da un sobrenombre, a mí me cuadra el de Precursora en el periodismo; yo he sido la primera mujer española que ha celebrado interviews con políticos y con artistas... [...] He sido la primera mujer que en España ha sido corresponsal de guerra, pues fui enviada a Marruecos por el Heraldo de $\mathrm{Ma}$ drid..." (Colombine en González Fiol, 1922: 20). Para Ana de Castro podemos aducir la cualificada opinión de Isabel Lousada (2012: 66): "A finalizar, notemos Ana de Castro Osório, na qualidade de jornalista pioneira, e os quadros da condição social das mulheres por si feitos a serem amplamente divulgados na imprensa. Dotada de uma escrita simultaneamente arguta e bela, Ana de Castro Osório abriu camino às jovens que lhe sucederam, que como ela se iniciaram nas lides jornalísticas e vocacionadas para tal, a elegeram como profissão".

${ }^{3}$ La oratoria es una de las acciones determinantes para la afirmación de las mujeres en el espacio público, como muy bien lo demuestra el caso de Ana de Castro (Lousada, 2012: 64-65, 71-73). Sobre las conferencias pronunciadas por mujeres puede verse una primera aproximación en Ezama (2012). 
que la tilda de "la mujer más prestigiosa de Portugal"; a partir de aquí la escritora española destaca el importante papel desempeñado por las mujeres en las luchas sociales y políticas de Portugal, como consecuencia de las cuales han obtenido ya el divorcio y el libre acceso a las carreras liberales. En la entrevista, Ana de Castro se declara defensora de los derechos de la mujer, apostando por la igualdad entre los sexos, "no por ser mujer, sino por su cualidad de ser humano"; la escritora portuguesa se extiende en detalles sobre las labores humanitarias desempeñadas por la Cruzada das Mulheres Portuguesas en favor de los soldados, pero también de las mujeres y los niños; coloca en primer lugar la lucha social y sólo en segundo la política.

Ana de Castro fue una mujer de asociaciones, extremo del cual da fe su correspondencia con feministas portuguesas y de otros países (Esteves, 1997), y que se manifiesta en la creación de varias de ellas, como la Liga Republicana das Mulheres Portuguesas (Esteves, 1991) o la Cruzada das Mulheres Portuguesas (Lousada, 2011). Fue también una defensora de los derechos de la mujer, desde las asociaciones que fundó y a las que perteneció (Grupo Portugués de Estudos Feministas, Associaçao da Propaganda Feminista), desde las revistas que creó (A Sociedade Futura, $A$ Mulher e a Criança, A Mulher Portuguesa, A Semeadora) (Esteves, 1999, 2001a, 2005), los libros que escribió (Ás Mulheres Portuguêsas, 1905) y las conferencias que pronunció (v.gr. "A mulher do Portugal e do Brasil", "As mulheres portuguesas", incluidas ambas en A Grande Aliança, 1924) (Lago dos Remédios, 2004; Lousada, 2012).

Fue también Ana de Castro una de las mejores representantes de la literatura infantil de base tradicional, que se desarrolla a partir de los años 70 del siglo XIX, siendo cultivada sobre todo por las escritoras (Ribeiro, 2003: 36 y ss.). En este ámbito fue primordial su labor, con su iniciativa de editar colecciones de cuentos como la de las series Para as crianças (18971935) y otras (Ribeiro, 2003; Esteves, 2003: 1020-1021; Alves, 2008); la escritora portuguesa fue recolectora de cuentos de tradición oral, algunos de los cuales reescribió en versión adaptada para niños (Ribeiro, 2003: 4651). Su amiga Carmen de Burgos subraya el papel de la portuguesa en este ámbito al comentar su cuento "La princesa muda", ilustrado por Leal da Cámara, traducido al español en 1921:
Ella fue la creadora de uno de los mayores elementos de renovación: la literatura tradicional para los niños.

Lo que importa en un movimiento no es el estudio de las fuentes tradicionales, sino su transformación en un sentimiento que actúe en el corazón de la raza; lo que importa no es el didactismo de los cuentos tradicionales, sino sensibilizarlos, darles esa forma definitiva y única a que los lleva Ana de Castro. Ella los recogió directamente del pueblo, muchas veces inéditos, los hizo de actualidad, los generalizó y los tornó capaces de actuar en una transformación anímica. (Burgos, 1921: 472-473).

Fue, en fin, la escritora y pedagoga portuguesa, una mujer integradora, extremo que testimonia su apuesta por la raza lusa, producto de la unión de Portugal y Brasil, si bien decantándose claramente hacia el primero de estos países. La creencia en una raza lusa como resultado de la unión etnocultural, geopolítica y económico-social entre Portugal y Brasil fue una utopía con la que los portugueses soñaron en el primer cuarto del siglo XX (Castro Leal, 2009), al igual que el sueño iberista ocupó a los españoles desde mediados del siglo XIX hasta bien entrado el siglo XX (Litvak, 1980; Ezama, 2008). Así lo trasluce el discurso utópico de Ana de Castro en los años veinte (Cordeiro, 2012: 72-75):

Esse sonho é a aliança firme e segura das duas Patrias irmãs, é o predominio da raça comum, é a imposição da nossa lingua como uma das mais faladas do mundo, é -finalmente!- a ressurreição duma nova fé e duma energía colectiva, tão grande que imponha ao mundo a repeito pelo que somos, criando uma nueva era de lusitanismo a engrandecer a historia! (Castro, 8 de mayo de 1923, en Castro, 1924: 13-14)

Deixai-me ter a esperança de que vós todos ficareis a viver comigo o maior sonho da Raça. Que o Brasil caminhe à frente das nações latino-americanas, mantendo a egemonia do progresso dirigente; como Portugal saberá manter a egemonia dos povos da Peninsula, como sempre o fez na historia do progresso e da civilização moderna, para se unirem na acção futura que havemos de realizar e impôr ao mundo. (Ibíd.: 36)

Y en esta utopía compromete a las mujeres, porque "A mulher foi sempre e em todos os tempos o elemento fixador das raças, porque é ela que verdadeiramente representa a continuidade tradicional das Pátrias" (Castro Osório, 1924: 42), en particular a las madres (Cordeiro, 2012: 47-63). 
A la altura de 1924 este proyecto utópico se desvanece (Castro Leal, 2009: 247), como se pone de manifiesto en una carta de Monteiro Lobato a Ana de Castro el 14 de mayo de 1925: “Tenho, por isso, a impressão que o Brasil e Portugal caminham em direções contrárias e nunca mais se entenderão" (en Lajolo, 2000: 10-11).

Por otra parte, en "A Grande Aliança” Ana de Castro denuncia el férreo dominio ejercido por España sobre Portugal:

Assim se explica o facto, talvez unico na historia, de um país, territorialmente pequeno, se desligar violentamente dum colosso que o esmagava num abraço de ferro, e correr para o seu posto de honra entre as nações libres, levando atraz de si as suas imensas e riquissimas colonias. (Castro, 1924: 32)

No obstante, en los artículos de la serie "As qualidades colonisadoras dos povos ibéricos" la escritora une los dos pueblos en uno solo en el proceso de la colonización, ya que ambos son "pueblos ibéricos"; con todo, la mayor parte de su discurso se centra en la labor colonizadora desempeñada por Portugal en Brasil. Conviene recordar que el iberismo estaba también presente en la utopía de la confederación luso-brasileña: la formación de un gran bloque luso-hispano-americano destinado a ser el centro de aglutinación de toda la latinidad (Castro Leal, 2009: 236). Pero además esta actitud integradora se corresponde con la perspectiva que domina en la revista en que estos artículos se publicaron: la Revista de la Raza. Publicación de Estudios Internacionales, órgano de la Alianza Hispano-Israelita, una publicación pro-sefardita que se convirtió a partir de 1924 en el portavoz de la Liga Internacional de Mujeres Ibéricas e Hispanoamericanas, a la que Castro pertenecía.

La Liga, fundada en 1924 por la mexicana Elena Arizmendi y presidida por Carmen de Burgos, contó con comités en la mayor parte de los países de América Latina, en Brasil, California, Francia y Portugal; en Brasil estaba representada por la periodista Avelina de Souza Salles y en Portugal por Elzira Dantas Machado (presidenta) y Ana de Castro Osório (secretaria) (Ezama, en prensa). A esta etapa corresponden los artículos publicados en Revista de la Raza que ahora presento.

Estos breves textos, escritos en lengua portuguesa, recogen prácti- camente todas las inquietudes personales de la autora. Son tres: el primero dedicado a la literatura tradicional portuguesa; el segundo, el más largo (dividido en cuatro capítulos) sobre las cualidades colonizadoras de los pueblos ibéricos; y el tercero es un comentario al libro de Carmen de Burgos La mujer moderna y sus derechos (1927).

La visión integradora la lleva Ana de Castro a todos los temas que trata: a la literatura, a la colonización y la causa de la mujer. En relación con la primera, al referirse a los cuentos infantiles de tradición oral afirma que "a literatura se pode dizer comum aos dois povos onde os escritores portugueses se confundem, lidos com igual entusiasmo dos dois lados do Atlântico"; aduce el uso de algunos libros de lectura para las escuelas primarias, que son los mismos en Portugal y en Brasil, probablemente los suyos propios (Lago dos Remédios, 2004); y bosqueja la historia reciente de la literatura infantil en Portugal hasta que llega a configurarse una literatu-

En relación con la colonización, Ana de Castro desmitifica el papel colonizador de Inglaterra y Holanda comparado con el de los pueblos antiguos como Cartago, y opina que sólo puede parangonarse a la labor de este último la de la Península Ibérica en América.

Por lo que concierne a la causa de la mujer, el elogio del libro de Carmen de Burgos La mujer moderna y sus derechos no es solo un tributo a la amistad entre ambas mujeres, sino sobre todo el fruto de una devoción compartida por la causa femenina y por Portugal. La visión integradora vuelve a asomar en la pluma de Ana de Castro, que dedica la parte final de su comentario a destacar la vinculación personal y literaria de Carmen de Burgos y de otras escritoras (Luisa Sigea y Vicenta Maturana) con el país vecino. No obstante, en su ideas sobre la mujer Ana de Castro y Carmen de Burgos parecen evolucionar a la inversa, y si la primera va desde la actitud combativa de Às mulheres portuguesas a otras más conservadoras en escritos posteriores, la segunda avanza desde la moderación inicial hacia una radicalización de sus ideas; la actitud de ambas pensadoras se explica por el muy distinto perfil de las respectivas repúblicas a las que sirven.

En definitiva, en la escritura de Ana de Castro, sea cual sea el tema de que se trate, la defensa de la nacionalidad portugesa ( $A$ minha patria) ra nacional a partir de los años 80 del siglo XIX (Esteves, 2003:1020-1022). 
parece estar por encima de cualquier otra causa, como demuestra el reciente libro de Cordeiro (2012: 80):

A preservação da raça lusa contitui um bem inestimável da identidade nacional no mundo. [...] A autora delega à mulher mãe portuguesa a responsabilidade pelo futuro racial e cultural do país. Só ela será capaz de reerguer Portugal como potencia imperial europeia. Ela é a via para a preservação da identidade nacional.

Recibido: $30 / 11 / 2012$

Aceptado: 02/04/2013

\section{Referencias bibliográficas}

Alves, Maria Angélica (2008), "A infancia, a leitura e o leitor, em Portugal e no Brasil (1880-1920)", ABZ da Leitura. Orientaçoes Teóricas, [portal web] Gulbenkian. Casa da Leitura, pp. 1-15.

$<$ 195.23.38.178/casadaleitura/portalbeta/bo/documentos/angelica_alves_a.pdf>

Ballesteros García, Rosa María (2003), “Cartas a una amiga portuguesa (Carmen de Burgos a Ana de Castro Osorio)", Andalucía contemporánea: actas del III Congreso de Historia de Andalucía, Córdoba, 2001, Córdoba: Caja de Ahorros y Monte de Piedad de Córdoba, Obra social y Cultural, pp. 21-38.

---- (2005), "Las distracciones misteriosas. Colombine y la masonería portuguesa", Aposta. Revista de ciencias sociales, 15, febrero, pp. 1-21<www.apostadigital.com/ revistav3/hemeroteca/ballesteros2.pdf>

---- (2006), "Soñadoras de dos mundos", Aposta. Revista de ciencias sociales, 30, julio, agosto y septiembre, pp. 1-47

<www.apostadigital.com/revistav3/hemeroteca/ballesteros3.pdf>

Burgos Seguí, Carmen de (1915), "Problemas de Portugal. Feminismo. Ana de Castro Osorio", Heraldo de Madrid, 30 de octubre, p. 3

---- (1921), "Literatura portuguesa", Cosmópolis, VII, pp. 464-474.

Castro Leal, Ernesto (2009), "A ideia de Confederaçao Luso-Brasileira nas primeiras décadas do século XX”, Revista de Estudios Filosóficos, 3, pp. 235-249.
Cordeiro, Celia Carmen (2012), Ana de Castro Osório e a mulher republicana portuguesa: veículo de regeneraçao da naçao e de preservaçao da identidade nacional, Lisboa: Fonte de Palabra.

Edfeldt, Chatarina (2006), Uma história na História. representações da autoria feminina na História da Literatura Portuguesa do século XX, Montijo: Câmara Municipal do Montijo.

Esteves, Joao (1991), A Liga Republicana das Mulheres Portuguesas -uma organização política e feminista- (1909-1919), Lisboa: Grafica 2000.

---- (1997), “A Colecção Castro Osório-Ana de Castro Osório (1872-1935)”, Leituras: Revista da Biblioteca Nacional, 1, outono, pp. 169-174

---- (1999), “O movimiento feminista em Portugal. Periódicos (1899-1928)”, Faces de Eva, 1-2, pp. 185-196

---- (2001a), “Os primórdios do feminismo em Portugal a 1ª́cada do século XX", Penélope, 25, pp. 87-112.

---- (2001b), “O movimiento sufragista em Portugal na 1a metade do século XX (1896-1947)", A mulher na história. Actas dos colóquios sobre a temática da mulher (1999-2000), Moita: Câmara Municipal, pp. 239-259.

---- (2003), “Osório, Ana de Castro”, en Antonio Novóa, Dicionário de Educadores Portugueses, Porto: Ediçoes Asa, pp. 1019-1026.

---- (2005), “Ana de Castro Osório", Diccionário no feminino: séculos XIX y XX, ed. de Zilia Osório de Castro y otros, Lisboa: Livros Horizonte, pp. 91-98.

---- (2011), “Contactos internacionais do Feminismo Português (1906-1928), "Contactos Internacionais do Feminismo Português (1906-1928), en Olhares sobre as Mulheres Homenagem a Zília Osório de Castro, Lisboa: CesNova.

Ezama Gil, Ángeles (2008), "El concepto de literatura nacional en la prosa de Juan Valera”, en Literatura y nación, Zaragoza: Prensas Universitarias, pp. 351-372.

---- (2010), "La Unión Ibérica de escritoras entre los siglos XIX y XX”, Estudios Portugueses. Revista de Filología Portuguesa, 10, pp. 57-78.

---- (2012), “La vocación pedagógica de Emilia Pardo Bazán”, Moenia, 18, pp. 417 437.

--- (en prensa), "La Liga Internacional de Mujeres Ibéricas e Hispanoamericanas y Cruzada de Mujeres Españolas”, Madrid: UNED. 
González Fiol, Enrique (1922), "Domadores del éxito. Carmen de Burgos (Colombine)", La Esfera, 24 de junio, pp. 19-20.

Lago dos Remédios, Maria José (2004), “Ana de Castro Osório e a construção da Grande Aliança entre os povos: dois manuais da escritora portuguesa adoptados no Brasil", Faces de Eva. Estudos sobre a Mulher, 12, pp. 1-10

< www.sbhe.org.br/novo/.../anais/109_maria_jose.pdf>

Lajolo, Marisa (2000), “Correspondência entre Anna de Castro Osório e Monteiro Lobato”, Revista Convergência Lusíada [Rio de Janeiro], XVII, pp. 305-311.

Litvak, Lily (1980), Latinos y anglosajones: Orígenes de una polémica, Barcelona: Puvill.

Lousada, Isabel (2011), "Pela Pátria: A Cruzada das Mulheres Porguguesas (19161938)", en 100 años de régime republicano: políticas, rupturas e continuidades, Lisboa: Comissao portguesa de História Militar-Ministerio da Defesa Nacional, pp. 667-688.

--- (2012), "Elos de progresso social e científico: contributo para a História das Mulheres Cientistas em Portugal", in Women, Science and Globalization: What's up?, Lisboa: Amonet, pp. 57-85.

http://run.unl.pt/bitstream/10362/8389/2/Amonet-Isabel\%20Lousada\%20p65. pdf

Ribeiro de Medeiros, Fátima (2003), Do fruto à raíz. Uma introdução às Histórias Maravilhosas da Tradição Popular Portuguesa recolhidas e recontadas por Ana de Castro Osório, Canelas: Gailivro.

\section{Apéndice}

\section{A tradição na literatura infantil portuguesa $a^{4}$}

Um povo é tanto mais digno de interesse quanto mais fundo mergulha na tradição do passado e melhor sabe manter o caráter próprio de sua civilização. O povo português encontra-se neste caso, coincidindo de uma forma interessantíssima em sua evolução e progresso material, bem evidente nos últimos anos, com uma renovação de sensibilidade tradicionalista que

${ }^{4}$ Agradezco la revisión de los textos a Wilheim Rodrigues. mantém sua originalidade.

De novo separado em 1640 do bloco Ibérico, Portugal retomou todas as suas colônias e domínios ultramarinos, fato tanto mais extraordinário e digno de admiração porque a nação portuguesa sofrera um período de enfraquecimento material e moral com o esforço de sua expansão, desproporcionada, ao número da população e seguido do desastre de Marrocos, em que ficou sem governo próprio.

Foi desse momento que se engrandeceu o domínio colonial da Holanda, que todo foi arrancado ao poder de Portugal e Espanha. Mas as nações ibéricas conseguiram o mais importante, que foi dominar definitivamente a América do Sul, onde criaram novos países do seu sangue e da sua língua. Portugal conseguiu vencer e expulsar os holandeses na Bahia e em Pernambuco e dar a essa nação imensa, que é o Brasil, uma unidade verdadeiramente admirável, muitas vezes superior à influencia inglesa nos Estados Unidos, porque essa foi feita com ódio à Inglaterra e por elementos escorraçados da mãe pátria, enquanto o Brasil foi formado pela melhor gente da nação, com entusiasmo, com amor, com a mesma ternura e carinho que se tem por um filho. E não só o Brasil, mas as nações Hispano-Americanas dão, nesse sentido, bem frisante testemunho da superioridade colonizadora da raça latina. Toda a superioridade da raça está bem demonstrada na imensidade dessa nova pátria, de sua origem, com a mesma língua, as mesmas tradições, a mesma religião, as mesmas caraterísticas e o mesmo sonho de grandeza futura, que fazem dos países Atlânticos um dos mais esplêndidos blocos raciais do futuro, com o qual é necessário que o mundo saiba contar.

As relações de amizade e íntimo parentesco moral são tão fundas entre os dois países lusitanos da Europa e da América -Portugal e Brasil- que a literatura se pode dizer comum aos dois povos onde os escritores portugueses se confundem, lidos com igual entusiasmo dos dois lados do Atlântico. Agora mesmo esse fato se caracterizou mais na aprovação e adoção de livros de leitura para as escolas primárias dos principais Estados do Brasil, igualmente adotados oficialmente em Portugal, o que dá uma união de conjunto aos dois povos, que será amanhã a sua maior força. Assim, as crianças portuguesas aprendem nas escolas o que é o Brasil nesses livros 
que lhes mostram como a verdade é uma das maiores glórias da sua raça e uma das mais formidáveis esperanças da civilização europeia, e as brasileiras criam raízes tradicionais de história e de raça que lhe dão um equilíbrio de povo com raízes, o que os coloca moralmente num ponto diferente e superior aos povos americanos do norte.

E não só os livros de leituras escolares primários são comuns aos dois países como a literatura infantil tradicional é lida com o mesmo agrado pelo grande público das duas nações irmãs.

Dissemos no princípio desse estudo, "que um povo é tanto mais digno de interesse quanto mais fundo mergulha nas tradições do passado e melhor sabe manter o caráter próprio de sua civilização". Ora, um dos pontos de apoio desta afirmação é a educação tradicionalista da alma infantil, que o povo português chegou momentaneamente a perder sob o ponto de vista literário, mas pela tradição moral do seu povo conseguiu manter ininterruptamente.

Em meados do século XIX, após a invasão francesa, em que o povo se encontrou quase que abandonado a própria sorte, rechaçado, entrou na Península a crise liberalista que a revolução francesa provocara e Napoleão favoreceu com a sua expansão guerreira através da Europa. Em Portugal, com semelhança flagrante do momento espanhol, essas lutas tiveram um caráter violento, tomando a chefia dos dois ideais que se enfrentavam (o absolutismo e o liberalismo constitucional) os dois príncipes irmãos da Casa de Bragança.

$\mathrm{Na}$ sua grande massa, o povo tradicionalista era pelo príncipe D. Miguel, que significava o poder absoluto do rei, mas as ideias quando estão no momento próprio do triunfo têm uma força tal que não há barreiras que as detenham e assim, com um pequeno exército mal armado e contrariando a maioria da vontade da nação, venceu o liberalismo.

Com esse triunfo o país ganhou em sua transformação material; deixouse penetrar de modernismo, abriu largamente a porta aos estrangeiros, às suas indústrias, ao seu comércio, a toda uma vida de fomento modernista a que não estava habituado. Mas com isso o povo perdeu, aparentemente, grandes qualidades e características interessantes que envergonhadamente fechou em si próprio, conservando-as como os seus deuses lares no seio das famílias, especialmente nas províncias, dificilmente penetráveis pela vida modernizada que as grandes cidades logo adotaram.

Nesse período, após a tentativa do maior artista literário da época, Almeida Garrett, que coligiu para o povo uma coleção interessante do romanceiro em verso, nada mais se fez no sentido de dar às crianças a ligação com o passado, que só os contos tradicionais lhe podem dar, criando uma alma própria para cada raça - por mais universais que pareçam algumas dessas tradições- que imprimem caráter para toda a vida.

Nesse período, moralmente perigoso para a nação, era vulgar dizer: "Não há em Portugal literatura infantil, fato tanto mais doloroso quanto é certo que a literatura portuguesa de todos os tempos é uma das mais ricas do mundo".

E na verdade não havia, dandose traduções às crianças em leituras recreativas e escolares, especialmente francesas, histórias de moral ridícula que carateriza essa especial literatura para colegiais, que a França pôs em moda e são tudo quanto há de menos belo e menos educativo no sentido inteligente da palavra.

Estava então em voga a literatura "recreio instrutiva" e o abuso do moralismo burguês nos livros destinados às crianças, reflexo ainda das teorias educativas de Rousseau.

Essa literatura pedante não conseguia instruir nem moralizar, pois criava nas crianças inteligentes uma reação irritante contra as ideias impostas, sufocando em todas as qualidades imaginativas a caraterísticas a cada raça.

A essa corrente se opuseram logo mentes como Dickens, mas só agora verdadeiramente conseguimos vencer a banalidade triunfante.

Em Portugal, porque essa influência foi muito limitada, atingindo só as classes citadinas mais cultas, que por moda se iam desnacionalizando em colégios estrangeiros, a inovação foi muito superficial.

Nesse momento, coincidindo com o grande impulso moral de ressurgimento nacionalista, provocado pela propaganda que se fez durante o centenário de Camões -o genial poeta da raça portuguesa, uma das grandes fi- 
guras que a civilização marcou para a imortalidade- no último período do século XIX as crianças lusitanas começaram a ter o que verdadeiramente se pode chamar de uma literatura própria e fundamentalmente portuguesa.

E foi então reconhecido que, ao contrário do que se dizia, o povo português podia ter para os seus filhos uma das mais belas e das mais opulentas literaturas, que o seu povo lhe conservara intacta com todas as caráterísticas próprias a uma verdadeira raça fundamentalmente nacionalista, como é a portuguesa.

Não há país nenhum que tenha tantas e tão belas tradições e que dá aos seus contos um caráter tão apropriado às suas faculdades criadoras e imaginativas, tanto na ciência, como na forma, que se estende e dilue um pouco e se compraz no descritivo do meio e das personalidades que en $\neg$ tram na fabulação, como é próprio de um povo que conseguiu através do mar o domínio de meio mundo, conservando as suas caráterísticas de dúvida ironista, misturada com uma grande força nas próprias qualidades.

Pode muito bem dizer-se que as últimas gerações portuguesas foram já formadas nessa verdadeira escola tradicionalista, conseguindo, exatamente porque correspondia à alma da nacionalidade, penetrar em todas as classes e influir junto ao povo, até agora fechado, das províncias, fixando-se em novas formas mais belas e cultas a sua tradição.

(Revista de la Raza, marzo de 1924, nº 108, pp. 5-6)

\section{As qualidades colonizadoras dos povos ibéricos}

Entre muitas das mentiras convencionais que o século 19 transformou em dogma, uma das que mais violentamente se contradiz, pelos fatos, é aquela que apregoa, acima de todos os povos, o povo britânico como o grande colonizador da história moderna.

Aqueles que atribuem à Inglaterra o moderno Carthago ainda podem ter alguma razão, porque o espírito do velho povo que dominou do norte da África os mares e os continentes onde podia chegar a traficância dos seus mercadores, ainda de longe se pode comparar ao interesse utilitário do predomínio inglês; mas os que pretendem ligar a civilização moderna à antiga, no mesmo espírito de vastidão inteligente do domínio, mais do que o da conquista, que espalha civilização dirigida pelo povo romano, esse nada tem que justifique a sua admiração pelas qualidades colonizadoras da Inglaterra.

A velha Carthago histórica ainda teve um momento idealista de expansão guerreira e domínio do gênio fulgorante de Aníbal, esmagado pelos interesses e invejas mesquinhas da plutocracia púnica, mas a Inglaterra nem com esse gênio ainda pôde deslumbrar o mundo, porque a sua ação e a sua grandeza vão sempre seguindo o caminho pesado e lento de sua vila econômica, sem interesse pela alma dos vencidos.

Os povos que na história da civilização moderna, afoitamente se pode afirmar que têm um poder dirigente e civilizador igual, por vezes superior, às grande civilizações dominadoras do passado, são os povos da Península Ibérica.

O que determinou, vejamos, o novo período da história moderna com a eclosão maravilhosa do Renascença?

Foram -sem dúvida nenhuma- o que vulgarmente se chamou Os descobrimentos.

Ora, essa realização magnífica que determinou a expansão e o predomínio mundial da civilização europeia foi encetada pelo povo português, logo seguido pela Espanha que harmoniosamente secundou o esforço do povo irmão, completando-se assim o que devemos chamar: o período ibérico da História da Civilização humana.

Os outros povos, como a Holanda e a Inglatera que seguiram no encalce, aproveitando aquilo que nós já não podíamos abarcar no desenvolvimento de todas as nossas energias espalhadas pelo mundo em ações variadas e violentas, são hoje considerados como grandes colonizadores, unicamente porque aproveitando o trabalho feito administraram sem grandeza de sonho dominador de almas, o que os povos penínsulares lhes foram deixando cair no poder.

E não se pode também negar aos povos ibéricos as qualidades administrativas e comerciais, tão reclamadas hoje para os povos anglo-saxões e germânicos, por quanto no período mais belo da expansão ibérica os por- 
tugueses fundaram no século 16 estabelecimentos comercias que deixaram profunda influência no Oriente, como Ceilão onde se distingue ainda bem nítida a nossa influência; Macau ainda português e em via de um franco ressurgimento; Malaca que foi um ponto estratégico do nosso comércio com o grande Oriente; a Índia de que guardamos dos dossos opulentos estabelecimentos comerciais; Gôa, a formosa cidade de Gôa, o grande orgulho e amor de Afonso de Alburqueque, que foi o maior dos conquistadores ibéricos, o fundador do poderio europeu no Oriente.

Se Portugal e Espanha, unidos no mesmo pensamento de justificado orgulho racial, iniciassem o novo período de expansão e grandeza da civilização ibérica -como temos esperança que suceda- uma das figuras que mais deverá merecer o estudo e a apoteose da história coletiva da raça será a desse grande capitão, o maior de todos, o Terribil, o Forte, o Justo, aquele que ao fulgor do seu gênio igual, e por vezes superior, aos maiores gênios conquistadores do mundo, levou a civilização de Ocidente e o cataclismo, que era uma das formas por meio das quais ela se impunha, ao vasto e misterioso Oriente.

Toda a tão apregoada obra de Lord Clive -de fato uma obra admirável que deu um Império à Inglaterra e mantém ainda hoje o seu predomínio na Índia- outra coisa não foi do que o seguimento metódico de obra colossalmente esboçada pelo gênio maravilhoso de Afonso de Abuquerque, o maior de todos.

Também os espanhóis nas Filipinas realizaram uma obra equivalente à obra dos portugueses, que foi tão forte, tão primacial, que perdura, apesar da dominação Norte-Americana.

Ali, ainda hoje o povo se diz com orgulho, hispano-malaio, sendo em pura língua espanhola que os grandes escritores se comunicam com a alma coletiva do mundo civilizado, como o conhecido grande Jesus Balmori e tantos outros.

Ora, se a língua é o verdadeiro traço fraternal das almas, nada poderá arrancar às Filipinas a sua filiação ibérica, nenhuma força material será bastante grande para arrancar a tradição aos povos que nasceram do gênio colonizador dos povos ibéricos.
A obra de descoberta, civilização e colonização dos dois povos penínsulares na América é de tal forma grande, que não cabe nos limites desta REVISTA e publicada junta, reservando para os seus traços gerais um próximo artigo.

(Revista de la Raza, agosto-septiembre de 1924, n $113-114$, p. 7)

\section{As qualidades colonizadoras dos povos ibéricos.}

\section{A obra dos portugueses na América}

O falar especialmente aqui da obra de Portugal na América não quer dizer que não sejam extensivas a todos os povos da Península Ibérica as honras que nos cabem na história da civilização mundial.

Juntos lutamos nos séculos XV e XVI, fazendo como nosso esforço o movimento maravilhoso da Renascença, que outra coisa não é senão o triunfo da ideia Ocidental sobre o Oriente vencido. Juntos fizemos a conquista do Novo-Mundo, que os homens imortais da nossa raça trouxeram a comunhão civilizadora da Europa, alargando o mundo que ainda era tão pequeno e tão limitado em sombras e mistérios para os homens da Idade Média.

A obra dos portugueses, como a dos demais povos da Península-agrupados sob a bandeira unida de Castela- realizada nos séculos XVI, XVII e XVIII é do mais perfeito paralelismo. Ela nos dá essa formidável criação de nações do novo Continente, que são o desdobramento admirável da raça, fixando para um futuro sem limites os seus destinos e aspirações.

Demos a essas filhas admiráveis do gênio ibérico o nosso sangue, a nossa alma, a nossa história o nosso sonho e - sobre tudo- lhes demos a língua, instrumento maravilhoso de posse eterna.

A obra de Portugal, unida em um só pensamento e em uma coesão perfeita nos limites das suas fronteiras, refletiu-se na coesão admirável do Brasil, uma das maiores nações do mundo. Nesse Brasil formidável que vai de lés a lés das suas fronteiras imensas, desde o Amazonas ao Rio de São Francisco, do Oceano Atlântico à linha divisória dos tratados, falando a mesma língua, regendo-se pelas mesmas leis, acatando as mesmas crenças, as mesmas tradições e costumes. 
A obra da Espanha abarca o resto da América do Sul em países autônomos, entrando pela América do Norte, numa Nação que será um dia a rival dos Estados Unidos, esse México tão caluniado e tão belo na força admirável da sua tradição e da sua Arte tão caraterística.

Todas essas Pátrias de nosso sangue foram criadas pelo gênio e pela persistência das raças da Península e por isso elas têm uma unidade e uma civilização tão próprias, que não haverá influências estranhas que as desliguem do nosso sonho e do encanto do nosso amor.

Nós, os portugueses, lutamos com uma coragem épica, num momento doloroso de fraqueza nacional, contra as tentativas de absorção dos holandeses e dos franceses no Brasil colonial. Apesar da fraqueza dos Governos de então, o heroísmo da raça foi tão grande que soubemos levar o Brasil unido até a sua independência coletiva, o que é um dos mais admiráveis traços da nossa história gloriosa.

Tornado independente, o Brasil é o mais legítimo orgulho de todos os portugueses, que não deixaram nunca de caminhar com um interesse tão sentimental quanto econômico.

É certo que a fortuna daquela imensa Nação está, em grande parte, na posse de portugueses e filhos de portugueses, todos se considerando brasileiros pelo coração, não perdendo os laços de ternura que os ligam à velha origem; mas também é certo que Portugal, ao contrário de outras grandes Nações que procuram expandirse e não têm para onde o fazer sem iludir os direitos alheios, só por amor à terra brasileira e a obra admirável de continuidade da raça, continuou ininterruptamente a sua emigração para o país independente, tendo na sua posse colonias que são verdadeiros impérios, e pouco a pouco afirmando-se novos núcleos de civilização, como o diremos em outros artigos a seguir.

O que é o Brasil de hoje como realizações e como possibilidades futuras tentaremos dizê-lo na continuação desse trabalho.

Por agora o que devemos marcar com firmeza é a obrigação que têm os países da Península em manter o contato intelectual, moral, e até material, com a América Ibérica, não cosentindo que essas grandes nações deixem perder o caráter marcado que lhes demos.
O triunfo e o progresso delas é o nosso triunfo e a afirmação gloriosa da nossa obra de colonizadores.

(Revista de la Raza, noviembre de 1924, no 116, p. 6)

\section{As qualidades colonizadoras dos povos ibéricos.}

\section{O Brasil}

Portugal, exatamente por se sentir apertado entre o domínio de Castela, que conseguira reunir todos os vários povos da Península num só Estado, e o mar largo e formidável que se lhe abria ao longo da costa, como único meio de expansão, caminhou destemidamente, numa inspiração racial genial, por essa larga via que lhe assegurou a eternidade do nome glorioso.

A política portuguesa, desde o início da nacionalidade, teve o sentido expansivo que era o instinto de conservação, que nos povos como nos indivíduos verdadeiramente determina as suas ações.

Assim, desde os primeiros tempos de luta pelo território conquistado dos mouros, que os olhos e a alma portuguesa os seguiam para além dos mares... Daí nasceram os primeiros esforços para a criação de uma frota, que dentro das possibilidades do tempo era já alguma coisa.

Sem nunca se desviar desse sentido de expansão, Portugal, melhor do que Castela seguiu sempre a política que verdadeiramente convém aos povos da Península, que estando embora ligada à Europa por uma parte do seu território dela se sente tão afastada pelos interesses e pela tradição como moral e materialmente nos ligamos à África, e depois da sua descoberta, à grande América.

Este é o instinto salvador de uma raça que impunha a si própria a formação histórica de um povo, que estava destinado a criar para a eternidade da terra uma nova civilização.

Os países ibéricos da América são a continuidade histórica da nossa raça e não há já possibilidade de morrerem povos que assim podem desdobrarse maravilhosamente fortes e opulentos sem perder a sua força e as suas qualidades internas. 
O Brasil será para Portugal a certeza magnífica do futuro, mesmo que outras não tivesse, porque a sua unidade é um dos fenômenos mais belos e mais extraordinários da História.

Quem vê no mapa essa extensão territorial que vai do Acre até o Ocea $\neg$ no, que engloba o Amazonas gigantesco até ao limite sul que faz fronteira com Uruguai e Argentina, pensa que esse país, hoje talvez o maior do mundo em território, deve ser um aglomerado de pequenos países prontos a desligarem-se ao primeiro repelão de mau gênio. Tal fato não acontece, porém, porque apesar das pequenas e naturais discussões políticas, que por vezes se dão nos Estados, nunca a ideia de separação vem como motivo de rebeldia e todos os brasileiros se indignam con essa ideia expressada por estrangeiros.

A unidade brasileira é fundamental e custa a compreender -mas o fato nos enche de orgulho-, como um pequeno povo,como numericamente foi Portuga1, conseguiu impor tão fundamentalmente as suas qualidades raciais, mantendo a tradição, a língua, os costumes e até as qualidades orgulhosas de caráter -a sentimentalidade violenta e a doçura no trato- numa extensão de território tão espantosa, e em certas regiões tão mortífera como foi, antes das regras higiênicas que fazem hoje de quase todo o Brasil um país ideal e admiravelmente habitável.

É necessário considerar que a descoberta do continente americano foi em 1500 pela frota de Pedro Álvares Cabral. São pouco mais de quatro séculos de uma colonização que foi quase sempre deixada ao acaso e a aventura do gênio português.

Em três séculos de colonização Portugal esboçou largamente o trabalho admirável que o Brasil, nação independente há um século apenas, conseguiu tornar uma realidade magnífica.

Visitar hoje o Rio de Janeiro não é uma curiosidade de viajantes e uma necesidade dos povos civilizados, porque esta cidade americana é das coisas que têm de se fixar como lugar de beleza marcado para a curiosidade universal.

O que a Natureza lhe deu, e é admirável, os homens o têm valorizado de tal forma que o Rio de Janeiro é hoje um ponto de atração mundial. O seu proprio clima foi modificado por tal forma pelas medidas higiênicas a que o sujeitaram, que nem sequer se pode hoje considerar difícil de suportar para qualquer raça que o procure.

De resto, em volta do Rio de Janeiro, que se estende preguiçosamente em frente ao grande Oceano, servido por Largas Avenidas asfaltadas ande os automóveis correm numa vertigem, há sítios na montanha que são oásis de eterna e doce frescura, mesmo no mais quente verão, como a Tijuca, Corcovado, a dois passos do centro da cidade; como Petrópolis, a linda estância da sociedade elegante; Teresopólis e inúmeras terras que a rodeiam dentro das suas maravilhosas florestas, como Parques de recreio.

O elemento português no Rio mistura-se rapidamente ao nacional, mas isto em vez de nos inferiorizar nos dá, pelo contrário, sensação de sentirmo-nos como se fosse essa a nossa própria terra. No comércio, na indústria, na literatura, nas escolas, no jornalismo e até no próprio funcionalismo os portugueses sentem-se em fraternidade completa com os brasileiros, sendo apenas uma minoria insignificante e sem importância social os que contrariam e odeiam a ação portuguesa, que acrescenta dia-a-dia algo às qualidades étnicas do povo.

O Rio de Janeiro pode bem classificar-se como uma cidade fundamentalmente lusitana, pouca ou nenhuma influência tendo nas suas caraterísticas as enormes e variadas colonizações, que para ali correm como um rio de sangue.

Veremos a seguir o que sucede em outras cidades e Estados do grande país americano de raça e língua portuguesa.

(Revista de la Raza, febrero de 1925, $\mathrm{n}^{\circ} 119, \mathrm{p} .8$ )

\section{As qualidades colonizadoras dos povos ibéricos}

\section{Os portugueses no Brasil. São Paulo}

Quem superficialmente conheça o grande e opulentíssimo Estado de São Paulo, sem dúvida o mais adiantado e economicamente mais bem organizado dos Estados Unidos do Brasil, parecer-lhe-á que a influência portuguesa foi batida pela italiana, cuja colônia é a mais numerosa de todas 
as que da Europa, América e Ásia vão, em demanda da fortuna, ajudar a grandeza da nova civilização que desperta.

No entanto, a colônia italiana, apesar de numerosa, não é, considerada globalmente, a mais rica e nem a sua influência bate a lusitana.

En 1914 era a colônia portuguesa do Estado de São Paulo a terceira em número, mas a primeira em riqueza global. Seguia-se em número ascendente a espanhola e a maior era a italiana. Depois disso veio a guerra e não podemos ainda estudar as atuais estatísticas, mas, não devem estar muito alteradas, porque vários fatores concorreram em favor da sua estabilidade.

Apesar, porém, da colônia italiana ter uma grande influência nesse Estado, espalhando-se por todo ele, não só nas indústrias e comércio das cidades, como nos trabalhos agrícolas, o que é fato é que essa imigração que vem apenas do século passado não foi suficiente para etnograficamente influir no Estado, que é fundamentalmente brasileiro, o que quer dizer: direto herdeiro dos portugueses que o colonizaram e lhe deram todas as qualidades e energias do seu sangue e do seu sonho de alma inquieta e ambiciosa.

O lusitanismo paulista representa, mais do que em qualquer outro Esta $\neg$ do, uma forte aristocracia territorial constituída pelos fazendeiros, quase todos descendentes das velhas famílias portuguesas e de alguns espanhóis, que juntos lideraram a fundação das novas pátrias de raça.

Quando, após a abolição da escravatura as novas emigrações europeias se encaminharam para o grande Estado, que é o empório mundial do café, encontraram um povo já formado, homogêneo e tão fortemente enraizado nas suas tradições ibéricas, que nenhuma influência tiveram, nem poderiam ter, no fundo étnico da raça. Influíram sim com o trabalho, com a valorização da inteligência, com o benefício do seu sangue e das suas qualidades de adaptação ao meio, que ficou sendo cada vez mais brasileiro.

O amor que os portugueses sentem por São Paulo é tão grande como o dos próprios naturais, confundindo-se naturalmente na residência à absorção estrangeira.

E realmente a ternura e orgulho pelo progresso desse enorme Estado, que é territorialmente tão grande como a França, justifica-se em absoluto porque de todos os da união brasileira é São Paulo o que indubitavelmente caminha na vanguarda do progresso intelectual e material.

Ao contrário do Rio de Janeiro, que tudo deve à Natureza que o envolve com a mais formosa moldura a sua opulência, desde a luz; a vegetação, ao mar, ao recorte grandioso das suas montanhas, ao encanto da sua bahia povoada de ilhas maravilhosas como contos da fadas; São Paulo é um dos mais espantosos esforços humanos que existe hoje no mundo.

Desde o clima, bastante variável oscilando entre o calor tropical, ao agreste dos invernos europeus, a capital paulista luta triunfantemente com a Natureza e consegue ser bela apesar de tudo. Edificada num planalto batido dos ventos, a 700 metros acima do nível do mar, a sua paisagem é triste e árida.

Depois da subida de Santos até o cimo da serra, a vegetação perde a opulência magnífica das regiões tropicais, e a cidade levanta-se imperiosa, senhora de si, consciente do seu papel civilizador e orientador, cheia de opulência, vibrante de trabalho; magnífica no esforço da sua indústria e do seu comércio.

Não se contentando de ser grande e de ser rica; é, como aspecto urbano, das mais bonitas e harmônicas do Brasil, talvez mesmo da América lusoespanhola.

O porto de Santos, que bem se pode chamar uma dependência da capital, ligados por uma linha férrea que é uma maravilha da engenharia mundial, e por uma estrada através da montanha, que os automóveis percorrem como um parque florido, é o escoante de todo o café que o Estado produz. E o Estado de São Paulo, sozinho, exporta tanto café como todas as outras regiões produtoras juntas.

Santos foi durante anos, e até séculos, considerado o «cemitério dos portugueses»: tantos e tantos eram os que lá morriam das más condições higiênicas em que trabalhavam. Mas, teimando sempre, a emigração portuguesa, numa persistência heroica que é a grande força da raça, nunca diminuiu, nunca abandonou o seu posto de honra. Hoje, completamente saneada, tambem Santos é uma bonita cidade edificada na baixa da serra, drenada por canais, florida de lírios brancos e de orquídeas, apertada entre o mar e a montanha com a sua vegetação opulenta como uma estufa formidável. 
Mais ainda do que a capital, Santos conserva o seu caráter fundamentalmente luso-brasileiro. Terra de trabalho e de labuta comercial quase exaustiva, as suas lindas praias, correndo em face do Atlântico, dão-lhe uma feição interessante de vida luxuosa e de prazer, que nos encanta.

Para nós, portugueses, o falar do Brasil e do seu progresso, enche-nos do mesmo orgulho e da mesma satisfação que sentimos ao falarmos da nossa própria metrópole ou das ilhas que são a sua continuação como do progresso das nossas grande colônias.

E a obra do nosso sangue é o esforço da nossa raça que não esmorece nem se deixa vencer nem absorver.

Lutando, contra todas as influências estrangeiras, o lusitanismo do Brasil é incontestável e já definitivamente triunfante.

A seguir veremos como os Estados do Sul, apesar da grande corrente germânica que os invadiu, não deixaram de ser fundamentalmente brasileiros, assim como Rio de Janeiro, a grande cidade cosmopolita, e como São Paulo, a terra admirável dos desbravadores do sertão.

(Revista de la Raza, abril de 1925, n 121, p. 6)

\section{"A mulher moderna e os seus direitos"}

É o título de um novo livro da grande escritora espanhola Carmen de Burgos, e só pelo título se compreende desde logo o que representa e o que vale o seu conteúdo.

Editado pela importante Casa Sempere, de Valência, faz parte da coleção das obras completas da autora que esta Casa está publicando e lançando no mercado como a maior regularidade.

Por empenho dos editores foi este trabalho intercalado entre os de maior interesse novelesco, que tem no país vizinho e em todos os países de fala castelhana um grande público certo e curioso. É que esta obra de compilação, de estudo e de crítica, se nada acrescenta à gloria do nome da autora, à beleza de sua obra literária, nem à autoridade do seu trabalho de jornalista, de socióloga e pedagoga, é uma boa ação realizada em favor da mulher de todos os países, mas da mulher que estuda, pensa, trabalha e vive, a mulher moderna como entendemos que deve ser e não a que vulgarmente assim se intitula, caricatura ridícula, manequim animado para iludir uns e desvirtuar as intenções das outras.

Os editores, que bem conhecem as exigências do mercado, compreenderam que a mulher espanhola, atravessando agora um momento difícil da sua vida psicológica, pois que o natural evoluir da sociedades a obriga a entrar definitivamente num campo de trabalho e atividade mental a que até hoje se tem conservado estranha, precisava de um livro como este, que fosse o seu guia no estudo do que tem sido o sexo femenino na sua ação social através do séculos.

Não se trata de um livro feminista nem mesmo se pode classificar como uma obra de combate, mas sim uma boa obra que se tornará indispensável para os países em que a ideia de uma humanidade composta de indivíduos igualados pelos direitos e pelos deveres, sem preocupações de sexos, está ainda muito embrionária.

A mulher moderna e os seus direitos é uma obra serena e forte, construída sobre uma base sólida que é a história, o direito e a sociologia. Não tem nenhum desses ridículos exageros que tanto escandalizaram a pacata sociedade dos fins do século XIX e com o nome de feminismo apenas serviram para acusar uma injustiça que se vinha prolongando através dos séculos, amortecida várias vezes por ilusões espirituais ou esmagada por acontecimentos materiais ainda mais violentos e trágicos.

Tudo quanto até hoje se tem dito da questão feminina e da história social da mulher através das civilizações históricas, das leis que as interessam e das diferenças que nos diversos países, pela comparação, torna o conflito social, a autora compendiou e classificou de uma forma clara e imparcial que tanto serve para a defesa como para a acusação.

Os primeiros capítulos são o resumo de quanto os homens têm dito de suas compaheiras, sem se lembrarem que dela vieram para a vida e pela sua mão entram na sociedade, onde as mães deveriam ter o primeiro lugar!...

Nestes primeiros capítulos de exposição ressalta um fato verdadeiramente curioso e que desmente quase todos os apodos e teorias que se vêm acumu- 
lando sobre o caráter feminino: é que não têm sido as mulheres mas sim os homens os que mais barulho têm feito, para nada!... Querendo impedir um movimento que corresponde em absoluto ao evolucionar da sociedade para alcançar o ideal de justiça, que é uma Humanidade única e dignificada, os inimigos do movimento de libertação feminina apenas têm conseguido chamar sobre a questão o interesse geral.

Entre o sexo feminino notam-se dois partidos perfeitamente diferenciados, correspondendo a dois movimentos distintos: um, o mais numeroso, aceita a situação da mulher dominada e inferiorizada pelo homem -embora no seu íntimo raramente esteja convencida de que o é, simulando-o para melhor viver- que dá toda a força às opiniões erradas em que o homen se compraz, com uma vaidade que não está de acordo com a superioridade que se arroga. O outro é constituído por uma diminuta minoria, que bem se pode classificar de élite entre a sociedade de ambos os sexos.

À parte alguns movimentos coletivos em que todos os tempos pretenderam -e conseguiram!- chamar a atenção do público indiferente sobre a questão de justiça, que representa a conquista dos direitos femeninos, como seja nos nossos dias as lutas das sufragistas, suportando heroicamente para esse fim os ridículos e os ódios, as mulheres em todos os tempos não se têm defendido das acusações com que os homens demostram a sua inferioridade e caminham para uma situação que as civilizações no seu máximo esplendor mecanicamente lhes impõem.

No livro A mulher moderna e os seus direitos, a autora recolheu tudo quanto diz respeito a essa questão, o que quer dizer que compendiou quanto se liga com o assunto sob as diversas modalidades da questão social, através do aspecto feminino.

No decorrer desta obra a que o sumário dos seus vastos XVI capítulos é suficiente para bem orientar os que queiram rapidamente fazer uma ideia do que tem sido a luta da mulher pela conquista do único direito que ninguém lhe deveria contestar, que é o de ser um indíviduo autônomo e consciente, o nosso país vem citado através da sua História, como dos seus costumes e leis, antigas e modernas, por vezes bem lisonjeramente.

É que a escritora ilustre que a Espanha tem como a sua primeira, e tão admirada é no seu país como na América, onde é reclamada como própria, sente pelo nosso país um verdadeiro carinho. Graciosamente se orgulha de ter nascido sob a proteção da bandeira portuguesa -seu pai era um grande amigo de Portugal, que trabalhava como vice-cônsul em Almeria- e em toda a parte nos defende com o mesmo entusiasmo com que defende a própria terra... porque o seu teórico cosmopolitismo é dos que se derretem facilmente, como um pedaço de gelo ao sol, se alguma opinião é adversa à Espanha.

O seu carinho pelo nosso país não obedece à moda, que nos faz agora tão recostados e lisonjeados pelos nossos visinhos sob muitos e variados aspectos, uns mais, outros menos sinceros... mas por uma simpatia espontânea e sincera que se vem manifestando ininterruptamente desde que há doze anos os acasos da guerra lhe tornaram difíceis as suas peregrinações para lá dos Pirineos e do Mediterrâneo.

Quando Portugal era ainda un mistério para os espanhóis e uma província de Espanha para os outros países... Carmen de Burgos ou "Colombine", no pseudônimo que ilustra na grande imprensa espanhola e ibero-americana, encetou uma propaganda tão contínua e tão desinteressada do nosso país que ninguém se viu obrigado a agradecer como um favor, nem sequer a reconhecer como un fato, que nos honra. E, no entanto, neste já largo espaço de tempo pode-se dizer que não há periódico ou revista, em que esta senhora escreva, que não tenha artigos ou gravuras com referências a tudo quanto em Portugal pode despertar algum interesse para o estrangeiro.

Muitas das suas novelas foram escritas aqui -algumas com assuntos e personagens portugueses, outras com referências e até com palavras iguais, que mostram muito bem quanto esta escritora se impregnou do ambiente e do sentir lusitano... embora a sua obra não seja lida como o devia ser em Portugal.

A naturalidade simpática com que se pôs a viver da nossa própria existência, sem deixar de ser profundamente espanhola, é um fenômeno tanto mais interessante quanto repetido entre as escritoras espanholas, que em diversas épocas têm demonstrado o seu amor por esta nossa linda terra acolhedora onde a diferença dormente da maior parte da gente mal corresponde ao âmago da Natureza e ao deslumbramento de uma paisagem que 
resume o encanto das mais belas do mundo.

Sabe-se que a erudita Luisa Sigéa, uma das mais brilhantes musas da corte a que presidia a Princeza $D^{a}$ Maria, era espanhola pela família e pelo nascimento e a Espanha voltou, pelos acasos da vida, tendo casado ali. Apesar disso, nunca pôde esquecer o lindo país de Portugal, que tanto encantou a sua admirável e brilhante mocidade, confessando-lhe sempre o seu amor e as suas saudades.

Dona Vicenta Maturana, uma poetisa gaditana, que no século XVIII foi muuito festejada e ocupou um lugar de destaque, não só nas letras como na corte de Fernando XII onde ocupava um lugar de camarista e confidente literária da rainha Dona Maria Josefa Amalia, foi uma grande amiga de Portugal onde residiu após a morte do seu pai na Guerra da Independência.

Depois de viúva, aqui regressou e morreu nos arredores de Lisboa. Nas suas poesias e novelas há muitas referências a nossas paisagens e nossos costumes.

Mais tarde também aqui residiu e aqui morreu a grande poetisa Carolina Coronado, que deixou uma tradição de muita simpatia na sociedade do seu tempo e ainda hoje é lembrada entre nós.

Não, é, pois, de admirar que o novo livro de Carmen de Burgos seja quase português, pelo interesse e amor que a sua autora tem pelo nosso país e pelo que reflete sob o aspecto português na questão social que muito bem classificou de A mulher moderna e os seus direitos.

(Revista de la Raza, agosto-septiembre de 1928, $\mathrm{n}^{\circ}$ 155-156, pp. 5-7)

\section{CROSSING TO THE OTHER SIDE}

THE AFTERWORLD AND AFTERMATH OF TRAUMA, WAR, AND EXILE IN ROSA CHACEL'S CIENCIAS NATURALES (1988)

\section{CHRISTINE ARKINSTALL}

University of Auckland (Nueva Zelanda) c.arkinstall@auckland.ac.nz

ABSTRACT: This article offers a reading of Rosa Chacel's Ciencias naturales as a testimony to the trauma and grief that Republican supporters suffered as a result of the Nationalists' victory in the Spanish Civil War, the consequences of exile, and the loss of the liberal Spain and cultural avant-garde with which Chacel identified. Whereas Chacel's three diaries have attracted many critical studies, hardly any exist on Ciencias naturales and none, to my knowledge, has linked Chacel's diaries with that novel. Arguing that Chacel's use of the diary in Ciencias naturales can be seen as a site of memory as developed by Pierre Nora, this study draws on theories of trauma to illuminate how Chacel's last work in her trilogy of memory novels bears witness to the original wound of the Civil War, constantly reiterating structures, symbols and motifs that articulate the paradigm of departure and return characteristic of traumatic memory. Finally, in its concluding section, the essay links Chacel's Ciencias naturales with José Ortega y Gasset's project of historical reason.

KEYWORDS: Rosa Chacel, novel, Ciencias naturales, exile, trauma, places of memory, Spanish Civil War, Second Republic, historical reason. 